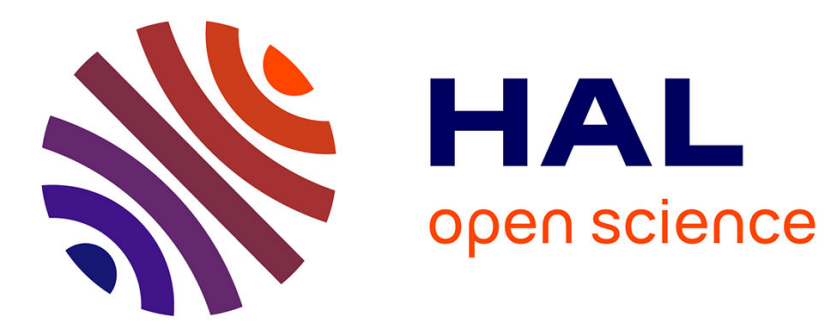

\title{
Hydrodynamic cavitation in microsystems. II. Simulations and optical observations
}

M. Medrano, Christian Pellone, P.J. Zermatten, Frédéric Ayela

\section{To cite this version:}

M. Medrano, Christian Pellone, P.J. Zermatten, Frédéric Ayela. Hydrodynamic cavitation in microsystems. II. Simulations and optical observations. Physics of Fluids, 2012, 24 (4), pp.047101. 10.1063/1.3699067 . hal-00700348

\section{HAL Id: hal-00700348 \\ https://hal.science/hal-00700348}

Submitted on 2 Jun 2020

HAL is a multi-disciplinary open access archive for the deposit and dissemination of scientific research documents, whether they are published or not. The documents may come from teaching and research institutions in France or abroad, or from public or private research centers.
L'archive ouverte pluridisciplinaire HAL, est destinée au dépôt et à la diffusion de documents scientifiques de niveau recherche, publiés ou non, émanant des établissements d'enseignement et de recherche français ou étrangers, des laboratoires publics ou privés. 


\title{
Hydrodynamic cavitation in microsystems. II. Simulations and optical observations
}

\author{
M. Medrano, C. Pellone, P. J. Zermatten, and F. Ayela ${ }^{a)}$ \\ Laboratoire des Ecoulements Géophysiques et Industriels, UJF Grenoble 1 - CNRS, BP 53, \\ 38041 Grenoble Cedex 9, France
}

(Received 13 July 2011; accepted 13 February 2012; published online 4 April 2012)

\begin{abstract}
Numerical calculations in the single liquid phase and optical observations in the two-phase cavitating flow regime have been performed on microdiaphragms and microventuris fed with deionized water. Simulations have confirmed the influence of the shape of the shrinkage upon the contraction of the jet, and so on the localisation of possible cavitating area downstream. Observations of cavitating flow patterns through hybrid silicon-pyrex microdevices have been performed either via a laser excitation with a pulse duration of $6 \mathrm{~ns}$, or with the help of a high-speed camera. Recorded snapshots and movies are presented. Concerning microdiaphragms, it is confirmed that very high shear rates downstream the diaphragms are the cause of bubbly flows. Concerning microventuris, a gaseous cavity forms on a boundary downstream the throat. As a consequence of a microsystem instability, the cavity displays a high frequency pulsation. Low values Strouhal numbers are associated to such a sheet cavitation. Moreover, when the intensity of the cavitating flow is reduced, there is a mismatch between the frequency of the pulsation of the cavity and the frequency of shedded clouds downstream the channel. That may be the consequence of viscous effects limiting the impingement of a re-entrant liquid jet on the attached cavity. (C) 2012 American Institute of Physics. [http://dx.doi.org/10.1063/1.3699067]
\end{abstract}

\section{INTRODUCTION}

Hydrodynamic cavitation in microsystems has been scarcely studied up to now. ${ }^{1-4}$ This paper concludes a quantitative study we have recently performed on various micromachined diaphragms and venturis, with hydraulic diameters ranging from $51 \mu \mathrm{m}$ to $104 \mu \mathrm{m} .{ }^{4}$ In the previous work, experiments were conducted with deionized water and nanofluids, and the relationships between the total pressure drop $\triangle \mathrm{P}$ and the flow rate $\mathrm{Q}$ were recorded and analyzed. Concerning a single liquid phase flow of density $\rho$ through a diaphragm of width $\mathrm{w}$, the relationship obeys

$$
\Delta \mathrm{P} \approx \frac{\rho}{2 \mathrm{C}_{\mathrm{d}}^{2}} \frac{1}{\mathrm{w}^{2} \mathrm{H}^{2}} \mathrm{Q}^{2},
$$

where $\mathrm{C}_{\mathrm{d}}$ is the discharge coefficient of the diaphragm and $\mathrm{H}$ is the height of the channel. Concerning a single liquid phase flow through a venturi, the regular losses through the diffuser may not be neglected, and the relationship obeys

$$
\Delta \mathrm{P}=\mathrm{aQ} \mathrm{Q}^{2}+\mathrm{bQ},
$$

where $\mathrm{a}$ and $\mathrm{b}$ are constants related to the contraction of the jet through the throat of the venturi and to the regular losses, respectively. The complete expressions of a and $b$ are detailed in Ref. 4. Their values can be experimentally found by plotting $\triangle \mathrm{P} / \mathrm{Q}^{2}$ as a function of $1 / \mathrm{Q}$.

\footnotetext{
a) Author to whom correspondence should be addressed. Electronic mail: frederic.ayela@ hmg.inpg.fr.
} 
A cavitation number $\sigma$ has also been defined:

$$
\sigma=\frac{2\left(\mathrm{P}_{\text {out }}-\mathrm{P}_{\text {vap }}\right) \mathrm{w}^{2} \mathrm{H}^{2}}{\rho \mathrm{Q}^{2}},
$$

where $P_{\text {vap }}$ is the vapour pressure of the fluid. $w$ is either the width of the diaphragm or the width of the throat of the venturi. The cavitation number provides an information about the lowest pressure in the stream, where the velocity reaches a maximum. We also note that $\mathrm{Q}_{\mathrm{cav}}$ is the flow rate above which the minimum pressure in the streamline falls down below $\mathrm{P}_{\text {vap }}$. The lower $\sigma$, the easier cavitation can take place or sustain.

The conclusions of our former studies on cavitation in microchannels may be summarized as follows. Microsystems possess smooth walls and the liquid was filtered out to prevent from clogging. Stream solid particles with size below $1 \mu \mathrm{m}$ were then expected to act as nuclei for the onset of cavitation. As a matter of fact, for both types of devices (diaphragm and venturi), the onset of cavitation was delayed when increasing the pressure drop, and occurred at $Q>Q_{c a v}$, according to the hypothesis above. Once two-phase cavitating flows were stated, desinent cavitation was studied by decreasing the pressure drop. Through microventuris, the bubbly flow and sheet cavitation vanished when $\mathrm{Q}<\mathrm{Q}_{\mathrm{cav}}$. Through microdiaphragms, cavitating bubbles could remain even if $\mathrm{Q}<\mathrm{Q}_{\mathrm{cav}}$, because of the presence of vortices with low pressure cores. That was confirmed by dispersing nanoparticles in the liquid. Because of the strong tension effect of vapor pocket on nanoparticles, no effect was expected. Surprisingly, the presence of nanoparticles, above a critical solid volume concentration threshold, had changed the onset of cavitation in microdiaphragms. We believe that nanoparticles trapped in the vortices interact and give way to solid aggregates whose size is sufficient to cross the threshold of cavitation.

A fundamental study of cavitation in microchannels may find applications in the area of jet atomization and high pressurized fuel injectors. The control of fuel spray atomization should help to enhance the efficiency of internal combustion engines. In fuel injection systems, the miniaturization goes together with increasing pressures. Diesel fuel injectors have small nozzle holes where it is recognized that cavitation takes place. Cavitation contributes to the liquid jet break-up at the nozzle exit. To know the influence of cavitation on jet atomization and to protect against unfavourable cavitation erosion, it is required to get a detailed knowledge of the mechanism of cavitation generation as well as of the collapse of the bubbles. Recent experiments have been performed, based on highspeed camera's observations or laser interferometry. ${ }^{5-7}$ However, the dimensions of the nozzles were limited at millimeter or sub-millimeter ranges.

Performing fine observations of cavitating flows through microsystems, in order to confirm the preliminary conclusions presented in the part I of the paper, was the challenge which has motivated this work. Section II is devoted to numerical calculations on single liquid phase flows through microdiaphragms and microventuris. Section III presents and analyzes the observations performed on both types of systems with pure deionized (DI) water. Section IV presents the conclusions.

\section{SIMULATIONS}

\section{A. General scope}

In order to study the various modes of flow occurring in the diaphragms and venturis, RANS calculations (Reynolds Average Navier-Stokes Simulation) were carried out using FLUENT code v6.2.

The Reynolds number is based on the hydraulic diameter of pipes whose section is rectangular. This number, calculated at the throat section (section of maximum velocity), remains moderate (maximum value of 3000). So, the flow can be regarded as laminar. Moreover, the fluid is supposed to be incompressible and the geometry to be two-dimensional.

The calculation is non-steady: by means of an iterative procedure the solution converges to a stable time-independent solution. The time scheme is a first order implicit scheme. The momentum equation is solved using a second order upwind scheme. The pressure-velocity coupling uses the SIMPLEC method. At each time step, 20 iterations are necessary to obtain the residual's convergence, 
with a relative precision of $5 \times 10^{-3}$. Independence in time of the flow-rate value, evaluated at various sections of the flow, is checked for each calculation. The time steps are continued until the pressure drop $\Delta \mathrm{P}=\mathrm{P}_{\text {in }}-\mathrm{P}_{\text {out }}$, across the diaphragm or the venturi, stabilizes. In the case of high flow rates, the pressure drop oscillates slightly around an average value, representing the fluctuations of the flow.

The constant pressure condition $\mathrm{P}_{\text {out }}=\mathrm{P}_{\mathrm{atm}}$ is assumed at the outlet. At the inlet a uniform flow velocity is imposed, corresponding to the flow-rate value. On each wall a zero-velocity condition represents adherence.

\section{B. Microdiaphragms}

Calculations were performed by selecting the same geometrical characteristics as those of one of the devices experimentally tested, that is: height $\mathrm{H}=126 \mu \mathrm{m}$ and width of the diaphragm $\mathrm{w}$ $=60 \mu \mathrm{m} .{ }^{4}$ With that sample, we found experimental values $\mathrm{C}_{\mathrm{d}}=0.93$ and $\mathrm{Q}_{\text {cav }}=210 \mu \mathrm{l} / \mathrm{s}$. The maximum calculated value of the flow rate is about $300 \mu \mathrm{l} / \mathrm{s}$ (throat velocity about $40 \mathrm{~m} / \mathrm{s}$ ), corresponding to a maximum Reynolds number of 3000.

In this kind of flow, from a numerical point of view, the developed vortices structures migrate faraway downstream. In order to ensure the disappearance of these structures at exit, the calculation field geometry was extended downstream by relocating the section "Out" (cf. Fig. 1 in Ref. 4) at a distance of $10550 \mu \mathrm{m}$. The grid used for calculations (cf. Fig. 1), has $\sim 90000$ cells. It was carried out in order to fix the size $\mathrm{d}_{1}$ of the first cell near the wall. In order to capture the vortices released by the diaphragm, the refinement of the mesh is carried out inside the throat and in the channel downstream. A calculation of the laminar boundary layer indicates that the boundary layer thickness varies between 0.3 and $3 \mu \mathrm{m}$. The choice of $0.6 \mu \mathrm{m}$ for the first cell size proved sufficient to ensure convergence with respect to the refinement. The time step is calculated using the mean velocity at the throat and the first cell size. So it depends on the flow-rate value, varying between 0.02 and 0.2 $\mu$ s. Usually, 300000 time steps are required to reach the calculation stabilization.

Laminar calculations were initially performed with a sharp edge of the forward facing step. That gave way to a discharge coefficient $\mathrm{C}_{\mathrm{d}} \approx 0.72$ corresponding to a contraction coefficient $\mathrm{C}_{\mathrm{c}}=0.66$. For two particular flow rates $(\mathrm{Q}=60 \mu \mathrm{l} / \mathrm{s}$ and $\mathrm{Q}=260 \mu \mathrm{l} / \mathrm{s})$, the calculations were also performed by doubling the number of mesh steps in the two directions (360000 cells) and the results were the same. However, there is a mismatch between the calculated discharge coefficient and the experimental one, as shown in Fig. 2. In fact, the jet contraction is very sensitive to the geometrical shape of the edge at the diaphragm inlet. As can be seen in Fig. 2, experimental and numerical curves become close to each other when taking into account a radius of curvature $\mathrm{r}=5 \mu \mathrm{m}$ (empty triangles). Further calculations (not presented here) have confirmed that with $\mathrm{r}>10 \mu \mathrm{m}$, the numerical relationship becomes insensitive to the radius and that it matches the

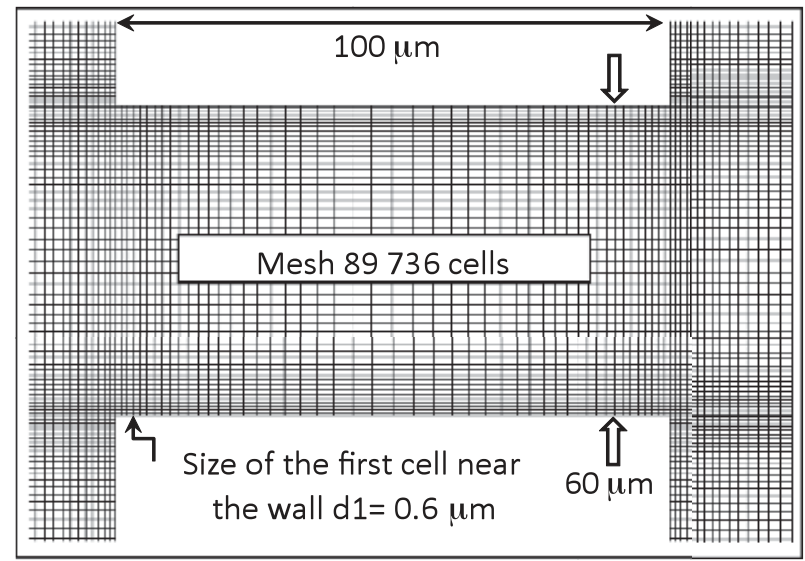

FIG. 1. Diaphragm $(\mathrm{H}=126 \mu \mathrm{m}$ and $\mathrm{w}=60 \mu \mathrm{m})$. 2D mesh (zoom). 


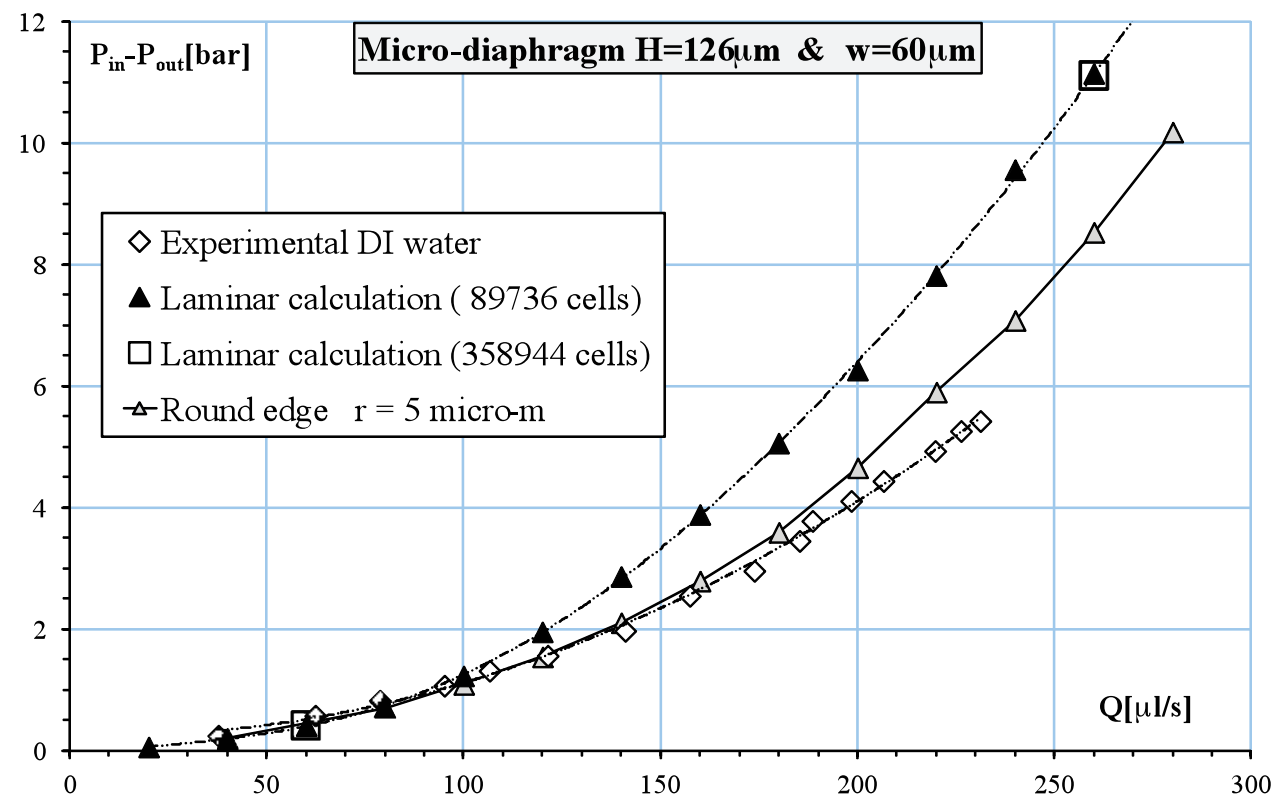

FIG. 2. Pressure drop $\Delta \mathrm{P}$ plotted as a function of the flow rate $\mathrm{Q}$ in the single liquid phase: comparison between experimental data and laminar calculations performed with a sharp (filled triangles and empty squares) and rounded (empty triangles) edge of the diaphragm.

experimental data. Optical or SEM imaging of the micromachined devices has demonstrated that the real radius was of the same order of magnitude. That parameter appears to be crucial on the flow rate-pressure drop relationship and so on the inception of cavitation.

Figure 3 highlightens the influence of the corner edge at the diaphragm inlet. The jet is definitely more contracted for the sharp edge (Fig. 3(a)) than for the rounded edge (Fig. 3(b)).

Figure 4 illustrates the velocity fields obtained at small (Fig. 4(a)) and high (Fig. 4(b)) flow rates, respectively. Calculations have been performed with rounded edges $(\mathrm{r}=5 \mu \mathrm{m})$ at the diaphragm inlet. Two different flow regimes are pointed out: a stable mode at low flow rates and a flapping mode at higher flow rates. In the case of the stable mode, the jet remains very smooth and sticks indifferently to one of the two walls. When the flow rate increases, because of non-steady instabilities, the jet breaks into several vortices structures, involving the flapping behavior. Although these calculations do not take into account the cavitation phenomenon, the velocity map is likely to match the low pressure areas where eddies may generate two-phase cavitating flows.

\section{Microventuris}

Calculations have been based on a device of height $\mathrm{H}=110 \mu \mathrm{m}$ and width of the throat $\mathrm{w}_{\mathrm{o}}=45 \mu \mathrm{m}$. Other sizes of the experimentally tested device are detailed in part I of the paper. ${ }^{4}$ The maximum calculated value of the flow rate is about $200 \mu \mathrm{l} / \mathrm{s}$ (throat velocity about $40 \mathrm{~m} / \mathrm{s}$ ), corresponding to a maximum Reynolds number of 2500. Laminar separation of the flow is expected to occur above a moderate flow rate.

The venturi total diffuser aperture is $7^{\circ}$. The length of the diffuser is $5 \mathrm{~mm}$. As a consequence, the outlet velocity of the fluid is rather low and the corresponding dynamic pressure is negligible in front of $\mathrm{P}_{\mathrm{atm}}$. In addition, the vortices structures reaching the outlet reabsorb very quickly downstream. Thus, the condition $\mathrm{P}_{\text {out }}=\mathrm{P}_{\mathrm{atm}}=$ constant can be used. The structured mesh used comprises $\sim 20000$ cells. A boundary layer calculation shows that, just downstream the throat, the first cell size, near the walls, has to be equal about $0.2 \mu \mathrm{m}$. Similar to the case of the diaphragm, by doubling the number of mesh steps both in the two directions, one obtains a refined mesh. No noticeable 


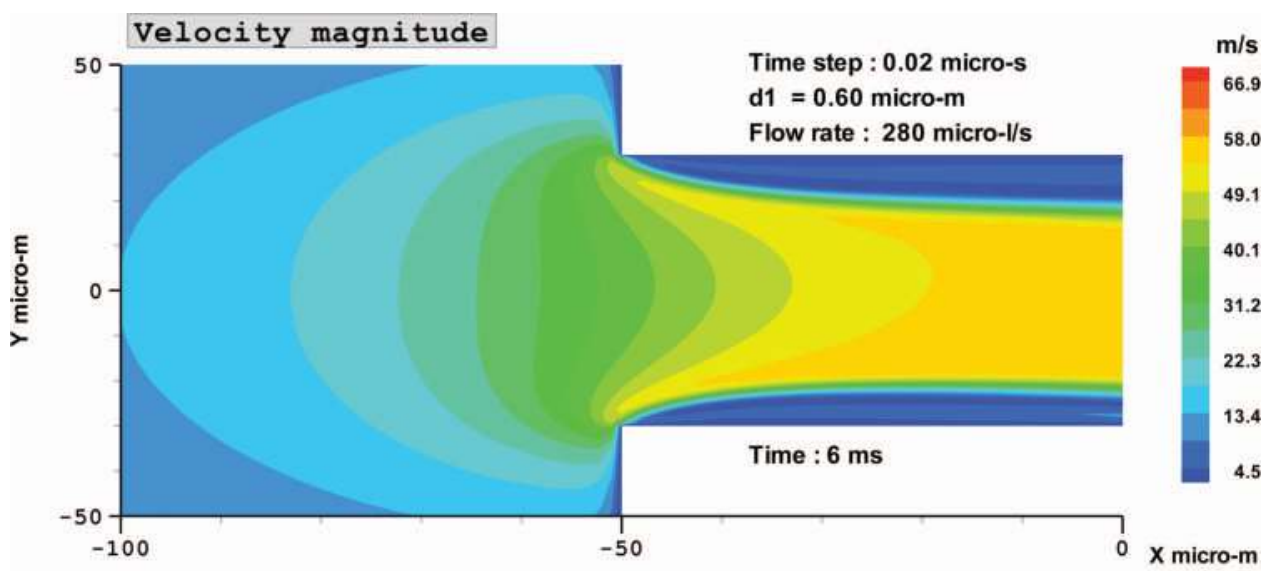

(a)

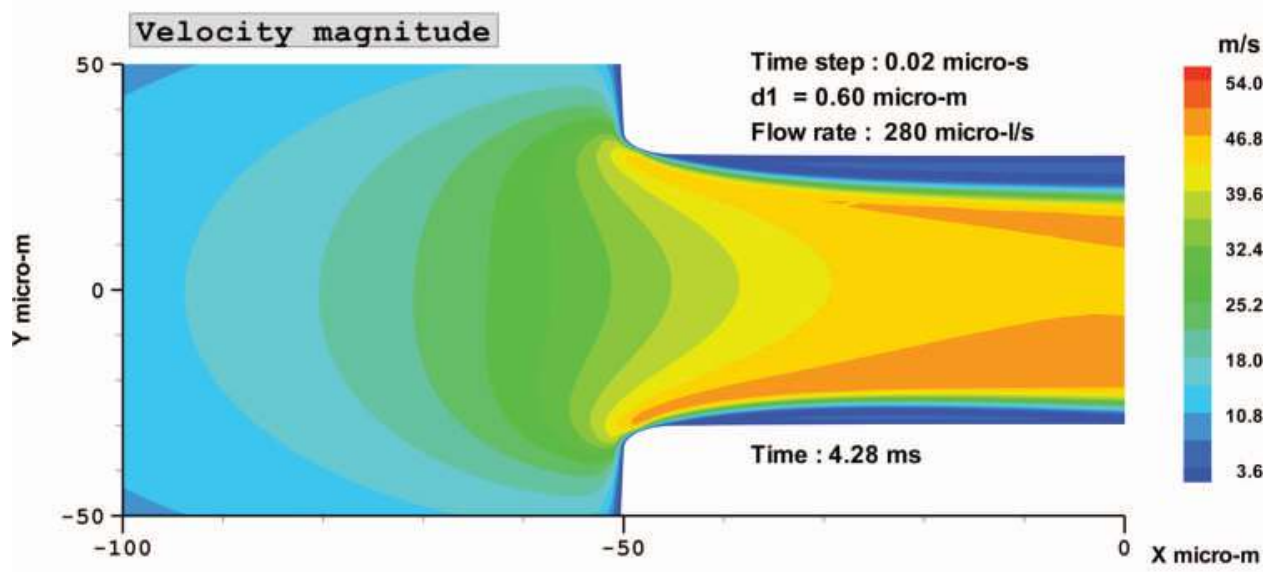

(b)

FIG. 3. Velocity fields at the inlet of a diaphragm $\mathrm{w}=60 \mu \mathrm{m}$ in width. The vertical height $\mathrm{H}=126 \mu \mathrm{m}$ : (a) with sharp edges and (b) with rounded edges (radius of curvature $\mathrm{r}=5 \mu \mathrm{m}$ ). The contraction of the jet is softened when flowing through a rounded diaphragm.

difference was recorded on the pressure drops obtained by means of the two meshes. For the set of flow-rate values, the time step varies between $0.002 \mu \mathrm{s}$ and $0.02 \mu \mathrm{s}$.

Figure 5 illustrates the results plotted via the curve $\Delta \mathrm{P} / \mathrm{Q}^{2}$ versus $1 / \mathrm{Q}$. Figure 5 presents the experimental results, the 2D, and 3D laminar calculations. Because of time consuming process, 3D calculations have been performed only for three different flow-rates values $(\mathrm{Q}=120,140$, and 160 $\mu \mathrm{l} / \mathrm{s})$. It should be noticed that all the data display a linear behaviour, with the same slope, that is, a confirmation of the validity of the polynomial relationship between $\triangle \mathrm{P}$ and $\mathrm{Q}$ as described in Eq. (2). It is also an indication that laminar separation, that occurs in the diffuser, may be simulated for these devices with a simple 2D model. However, the 2D model fails in predicting the $\mathrm{C}_{\mathrm{v}}$ coefficient related to the contraction of the jet through the throat of the venturi (see Eq. (10) in Ref. 4). The reason comes from the fact that the side walls are not taken into account in the $2 \mathrm{D}$ calculations. The values resulting from a 3D calculation are close to the experimental ones, with a relative error of $5 \%$.

Two different regimes are shown in Fig. 6. At a low flow rate $(\mathrm{Q}=20 \mu \mathrm{l} / \mathrm{s})$, the outgoing jet remains perfectly rectilinear and stable, and no separation occurs, as observed experimentally. ${ }^{4}$ At higher flow rates $(\mathrm{Q}=180 \mu \mathrm{l} / \mathrm{s})$, the jet sticks randomly, towards one of the two walls, and 


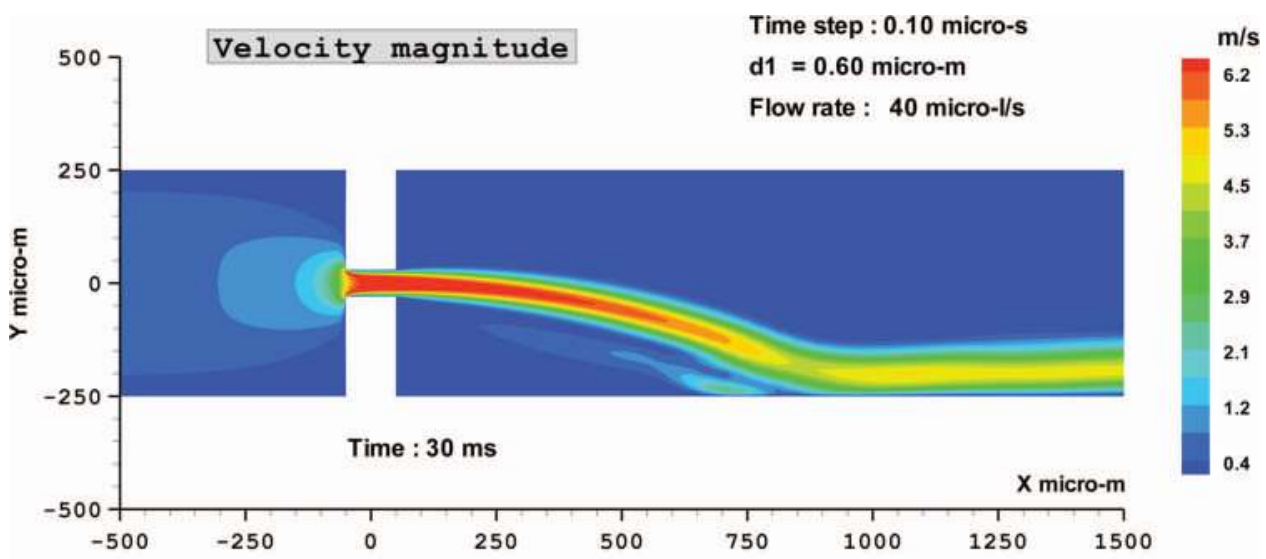

(a)

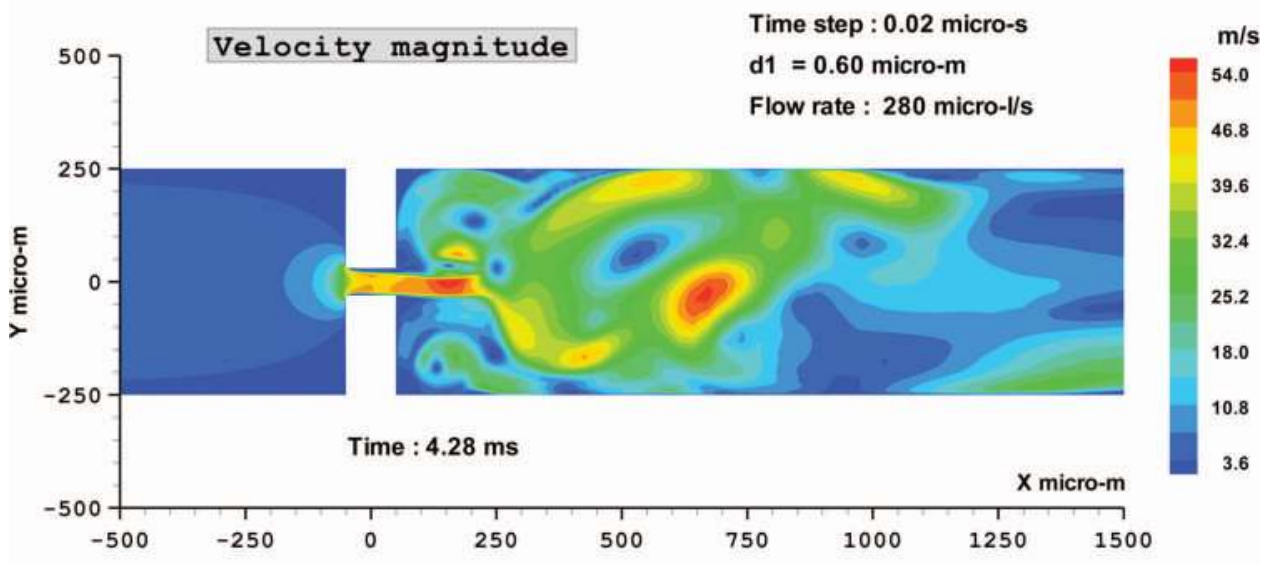

(b)

FIG. 4. Velocity fields downstream a diaphragm with rounded edges, $\mathrm{w}=60 \mu \mathrm{m}$ in width. The vertical height $\mathrm{H}=126 \mu \mathrm{m}$. (a) Flow rate $\mathrm{Q}=40 \mu \mathrm{l} / \mathrm{s}$ and (b) flow rate $\mathrm{Q}=280 \mu \mathrm{l} / \mathrm{s}$.

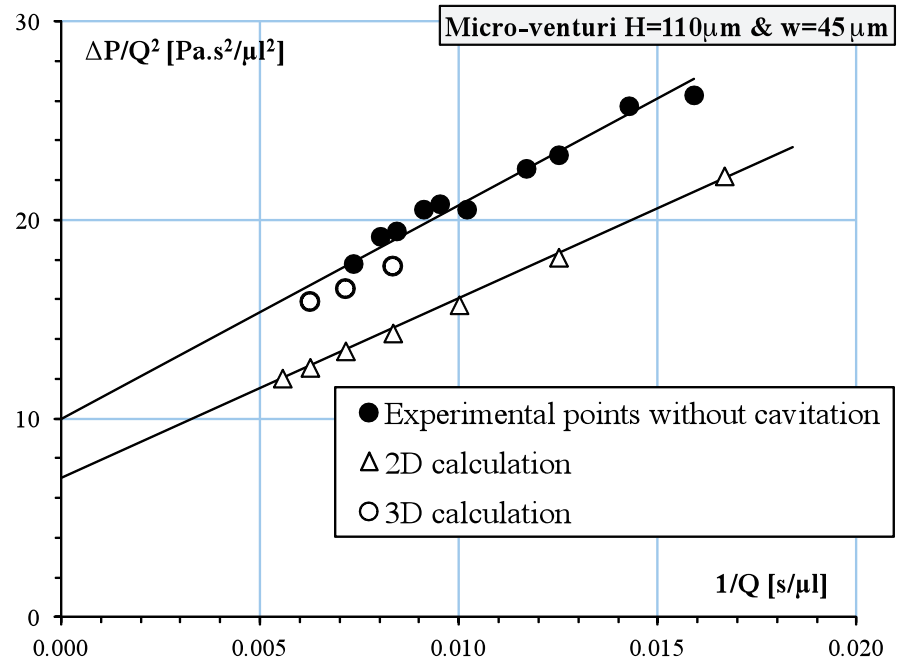

FIG. 5. Hydrodynamic relationship, in the single liquid phase, for a microventuri $(\mathrm{H}=110 \mu \mathrm{m}$ and $\mathrm{w}=45 \mu \mathrm{m})$. Comparison between experimental data, 2D (fluent laminar), and 3D calculations. 


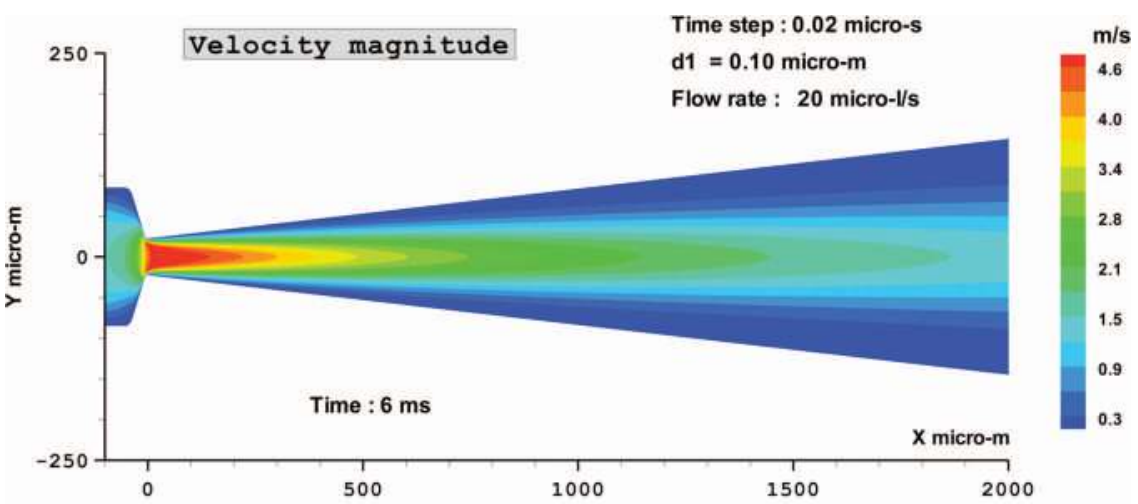

(a)

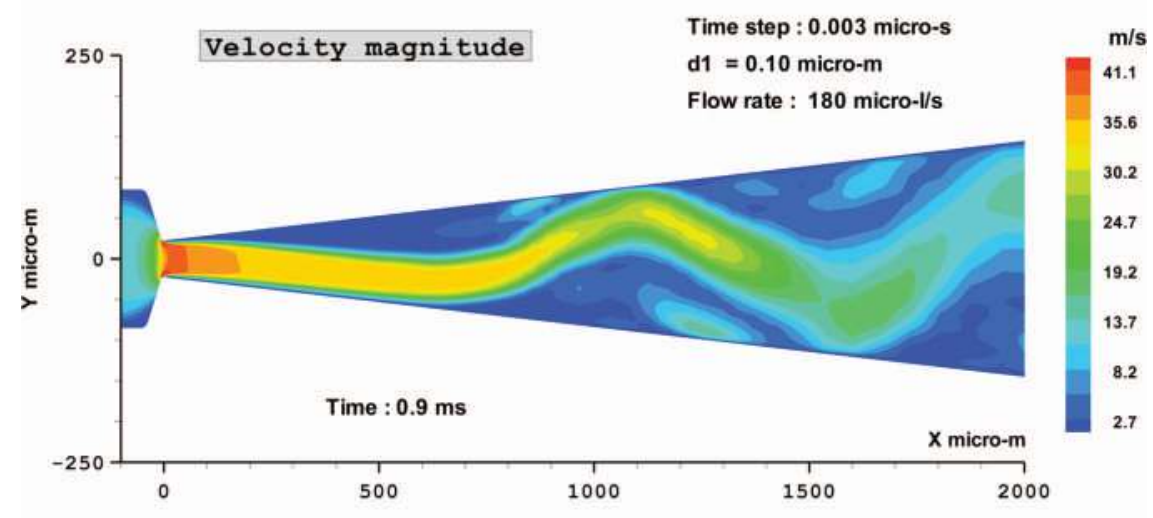

(b)

FIG. 6. Velocity fields downstream a microventuri $\left(\mathrm{H}=110 \mu \mathrm{m}\right.$ and $\left.\mathrm{w}_{\mathrm{o}}=45 \mu \mathrm{m}\right)$. (a) $\mathrm{Q}=20 \mu \mathrm{l} / \mathrm{s}$ and (b) $\mathrm{Q}=180 \mu \mathrm{l} / \mathrm{s}$.

progresses downstream according to a stable undulatory form. The jet does not oscillate but touches the walls in various points. Downstream, the jet becomes increasingly diffuse.

A pressure field map calculated for a flow rate $\mathrm{Q}=180 \mu \mathrm{l} / \mathrm{s}\left(\mathrm{P}_{\text {out }}=0.98\right.$ bars, $\mathrm{Re}=2323$, and $\sigma=0.14$ ) is reported in Fig. 7. The pressure coefficient $\mathrm{C}_{\mathrm{p}}$ that is reported is defined by

$$
\mathrm{C}_{\mathrm{P}}=\frac{\mathrm{P}-\mathrm{P}_{\text {out }}}{1 / 2 \rho \mathrm{Q}^{2}} \mathrm{w}_{0}^{2} \mathrm{H}^{2},
$$

where $\mathrm{P}$ is the local pressure. $\mathrm{C}_{\mathrm{p}}=-0.14$ corresponds to $\mathrm{P}=\mathrm{P}_{\mathrm{sat}}$. A first low pressure cavity increases and attaches itself to one of the two walls. This cavity remains stable and develops in a super-cavitating mode $1 \mathrm{~mm}$ downstream the throat. This behavior is in perfect agreement with the experimental results presented below.

\section{OPTICAL OBSERVATIONS}

\section{A. Experimental setup}

Two specific test sections were dedicated to the recordings of snapshots and high-speed movies of cavitating flow patterns, respectively. The setup is represented in Fig. 8.

Snapshots were performed on some of the silicon-pyrex microchannels (diaphragms and venturis) formerly characterized by the pressure drop versus flow-rates relationships. An image ProX (Lavision) high resolution CCD PIV camera with a maximum possible spatial resolution of two million pixels was mounted over a Leica S8 APO stereomicroscope focusing on the sample under 


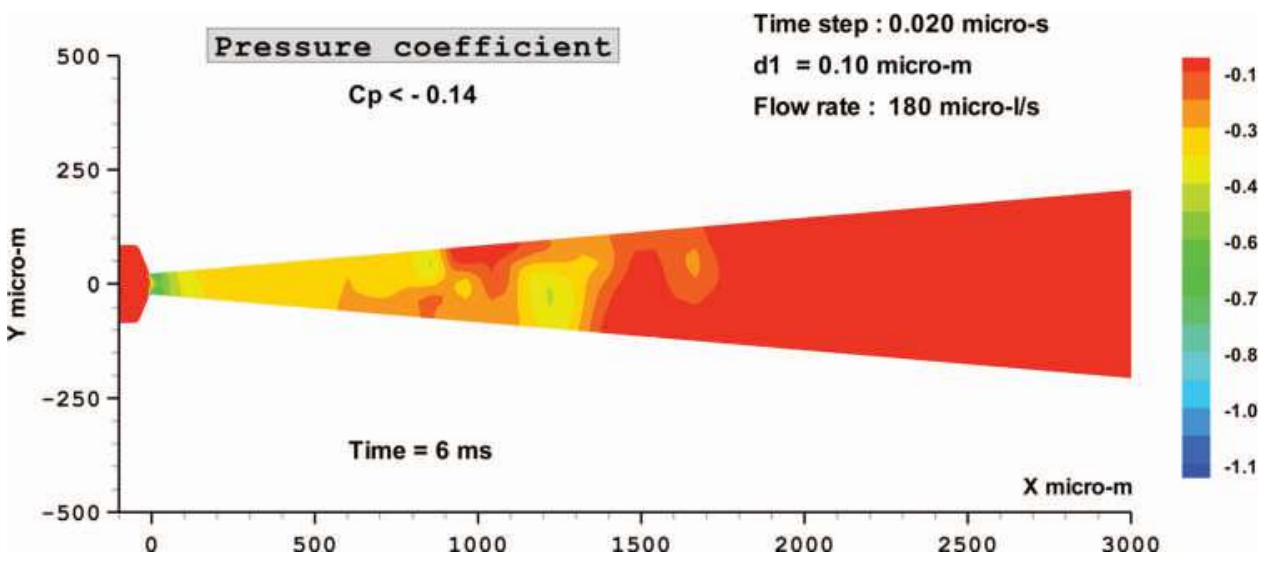

FIG. 7. Pressure repartition downstream a microventuri $\left(\mathrm{H}=110 \mu \mathrm{m}\right.$ and $\left.\mathrm{w}_{\mathrm{o}}=45 \mu \mathrm{m}\right)$ with a flow rate $\mathrm{Q}=180 \mu \mathrm{l} / \mathrm{s}$.

test (Fig. 8(a)). The sample was illuminated by a Quantel pulsed laser YAG (pulse duration: $6 \mathrm{ns,}$ repetition rate: $15 \mathrm{~Hz}$, beam diameter: $3 \mathrm{~mm}$, wavelength: $532 \mathrm{~nm}$ ). Because of the short pulse width of the laser, stop-motion pictures of the two-phase flow could be recorded. However, the frame rate of the camera $(15 \mathrm{~Hz})$ did not allow to record the detailed evolution in time of the cavitating bubbles.

A second setup has then been designed, with a $5 \mathrm{~W} \mathrm{CW}$ laser Millenia (beam diameter: 2-3 mm, wavelength: $532 \mathrm{~nm}$ ) and a Phantom CCD camera which is able to record up to $67 \times 10^{3}$ frames per second (fps) with an exposure time of a few microseconds. Unfortunately, that test section was not efficient with the hybrid silicon-pyrex devices, since the light reflected from the silicon part has resulted in an over-illumination of the sensors of the camera. So, a new design of fully transparent microchannels has been stated, as described in Fig. 8(b). A thinned silicon wafer is anodically bonded onto a pyrex substrate. The microchannel is lithographed and reactively ion etched through the whole thickness of the silicon. Another pyrex cap, with drilled apertures, is then anodically bonded onto the channel. The laser beam, focusing on the rear side of the channel, is tilted from the axis of the camera. When a single phase fluid flows through the channel, light is not scattered and a black frame is recorded. When cavitating bubbles are present, light is scattered and images of cavitation are captured by the camera (Fig. 8(b)) in the form of bright visual data. Since the height of the channel is in the sub-millimeter range, it prevents from multiple diffusion of light.

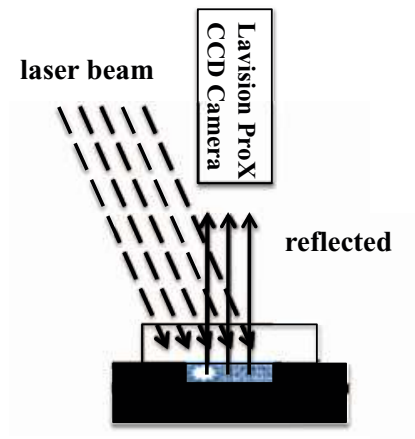

(a)

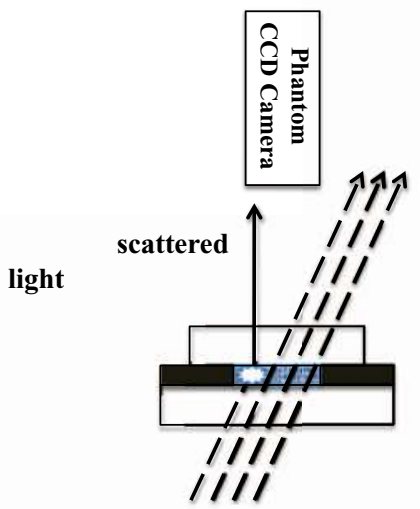

laser beam (b)

FIG. 8. Sketch of the experimental setup devoted to record (a) snapshots and (b) high-speed movies of two-phase cavitating flow patterns through (a) pyrex-silicon microchannels and (b) pyrex-silicon-pyrex microchannels. 
The exposure time (from $2.5 \mu \mathrm{s}$ to $41 \mathrm{~ms}$ ) was slightly below the delay between two frame captures (from $15 \mu \mathrm{s}$ to $41.6 \mathrm{~ms}$ ).

The whole experimental setup used to reach cavitating flows has been presented in the part I of the paper. ${ }^{4}$ By controlling inlet and outlet pressures $\mathrm{P}_{\text {in }}$ and $\mathrm{P}_{\text {out }}$, we impose a water flow rate $\mathrm{Q}$ through the channel. The flow rate $\mathrm{Q}$ is recorded and the experimental relationship between $\triangle \mathrm{P}=\mathrm{P}_{\text {in }}-\mathrm{P}_{\text {out }}$ and $\mathrm{Q}$ is compared in Eq. (1).

\section{B. Microdiaphragms}

Snapshots were recorded with the Lavision ProX camera downstream a micro-orifice $\mathrm{w}=60$ $\mu \mathrm{m}$ in width, entrenched inside a channel of width $\mathrm{W}=510 \mu \mathrm{m}$. The height of the channel was $\mathrm{H}=126 \mu \mathrm{m}$. That device had been previously characterized and the experimental relationship between the pressure drop $\triangle \mathrm{P}$ and the flow rate $\mathrm{Q}$ is recalled in Figure 9. Due to the lack of roughness of the walls and to the lack of solid nuclei in DI water, a metastable liquid state remains until a sharp transition to cavitation suddenly occurs; at a given pressure drop $\triangle \mathrm{P}$, the flow rate is reduced as a consequence of the appearance of a bubbly flow. By increasing $\triangle \mathrm{P}$ in the cavitating flow regime, the increase of the flow rate is then below the increase of the monophasic flow rate. Data pointed with arrows in Fig. 9 are related to snapshots presented in Fig. 10. They were recorded by decreasing the pressure drop from the highest cavitating flow rate (Fig. 10(a)) down to the vanishing of cavitation (Fig. 10(f)).

In Fig. 10, the black area corresponds to the top of the channel. The grey area corresponds to the bottom of the channel, and speckles are due to the scattering of light at the bottom of the etched channel. Vapour clouds are clearly noticeable. The fluid is flowing from the left to the right. Figure 10(a) corresponds to the smallest cavitation number as defined in Eq. (3). A vapour cloud expands downstream the diaphragm, over a length of $\approx 1.5 \mathrm{~mm}$. Although there is a strong bubbly flow, a liquid jet can pass through the diaphragm and through the channel. The vapour cloud may be located either on one side of the channel (Fig. 10(a)) or on the opposite side (Fig. 10(b)). In fact, vapour clouds are randomly flipping from one side to the other, as could be recorded for a fixed flow condition (Figs. 10(c) and 10(d)). It is the liquid flow emerging the diaphragm which is flipping

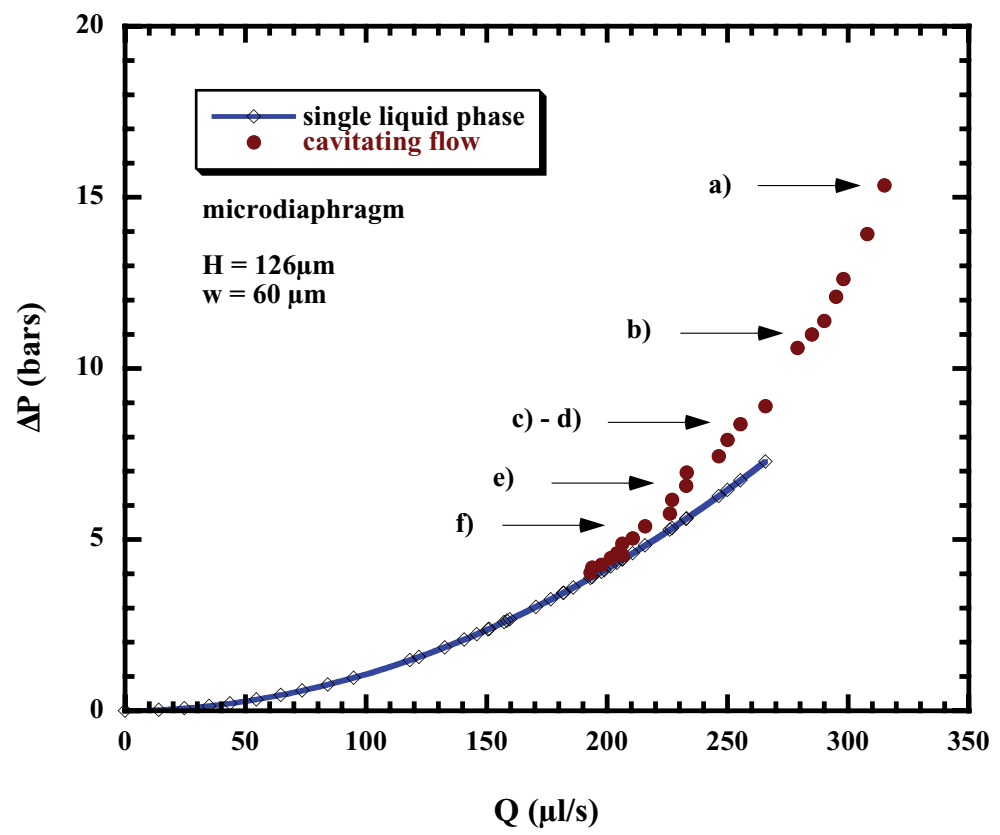

FIG. 9. Experimental relationship between the pressure drop across a microdiaphragm and the flow rate. The solid line corresponds to the single liquid flow and the filled circle points correspond to the cavitating two-phase flows. The arrows are related to the snapshots presented in Fig. 10. 


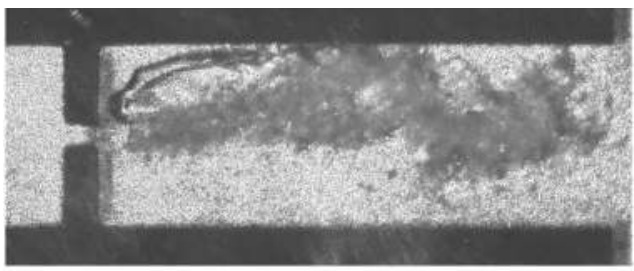

(a)

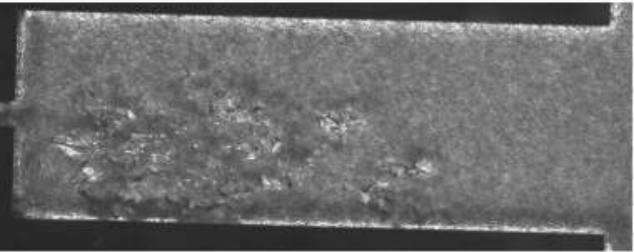

(c)

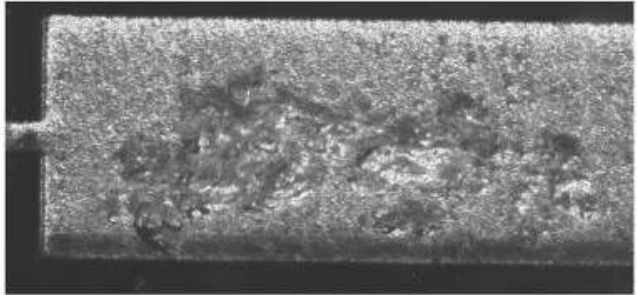

(e)

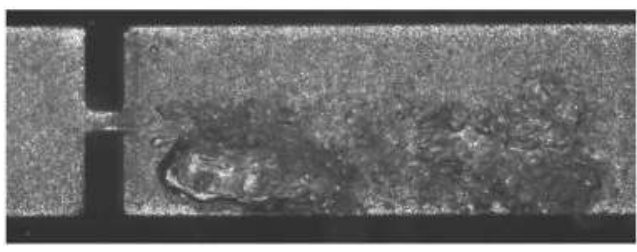

(b)

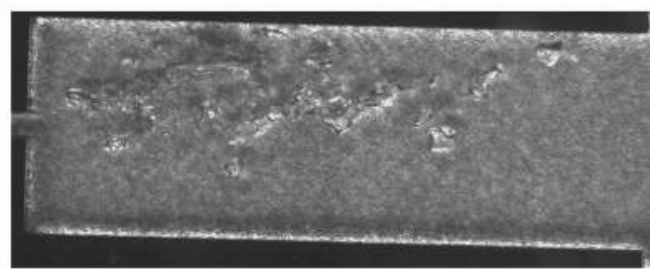

(d)

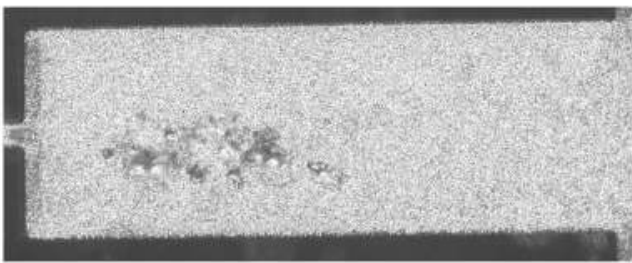

(f)

FIG. 10. Snapshots of cavitating two-phase flows recorded under different hydrodynamic conditions. The width of the diaphragm is $\mathrm{w}=60 \mu \mathrm{m}$, the width of the channel is $\mathrm{W}=510 \mu \mathrm{m}$. The height of the device is $\mathrm{H}=126 \mu \mathrm{m}$. Reynolds numbers $\operatorname{Re}_{\mathrm{d}}$ are calculated in the diaphragm. The exposure time of each picture is $6 \mathrm{~ns}$.

and impacting alternatively one wall and another. By decreasing the pressure drop, the amount of bubbles is strongly reduced (Fig. 10(f)). Cavitation is here the consequence of high shear layers and of the formation of eddies at the boundary of the emerging jet.

Cavitating flows have then been characterized with the help of the Phantom camera through a transparent microdiaphragm whose sizes were $\mathrm{H}=160 \mu \mathrm{m}$ and $\mathrm{w}=54 \mu \mathrm{m}$. The video associated with Fig. 11 is a succession of captures recorded at a rate of $54 \times 10^{3} \mathrm{fps}$ during $10 \mathrm{~ms}$. The exposure time for each frame is $17.66 \mu \mathrm{s}$. The hydrodynamic conditions were $\mathrm{P}_{\text {in }}=7 \mathrm{bars}, \mathrm{P}_{\text {out }}=1 \mathrm{bar}$, and the average velocity of the fluid through the diaphragm is around $28 \mu \mathrm{m} / \mu \mathrm{s}$, the cavitation number $\sigma=0.25$ and $\mathrm{Re}_{\mathrm{d}} \approx 2300$ in the diaphragm. The succession of the frames demonstrates that the liquid jet is merging from the diaphragm and impacting on the wall located in the left side of the stream. The recirculation areas, the intensity of the vapour phase at the boundary of the jet, and the shear rate between the liquid jet and the walls are clearly noticeable. As the exposure time of the camera was $17 \mu \mathrm{s}$, the ways followed by single bubbles nearby the jet appear as small white threads, when it is observed frame by frame. The two-phase flow is consistent with the hypothesis of high shear rate cavitation.

Videos have also been recorded with $\mathrm{P}_{\mathrm{in}}=3.56$ bars and $\mathrm{P}_{\text {out }}=0.11$ bars. The average velocity through the diaphragm is $21 \mu \mathrm{m} / \mu \mathrm{s}$ and the cavitation number is $\sigma=0.04$. The first one is a succession of captures recorded during $1 \mathrm{~s}$ with a rate of $28 \times 10^{3} \mathrm{fps}$ and with an exposure time of $9 \mu \mathrm{s}$ (view video in Ref. 8). The second one has been recorded during $1 \mathrm{~s}$ with a rate of $24 \mathrm{fps}$ and with an exposure time of $41 \mathrm{~ms}$ (view video in Ref. 8). The recirculation of the fluid is clearly noticeable. Since the output pressure is low, the liquid jet does not deviate downstream from a linear direction.

The first visualisations of cavitating flow patterns through microdiaphragms have been published by Mishra and Peles. ${ }^{2}$ They were recorded with a minimum exposure time of $2 \mu \mathrm{s}$. In these 

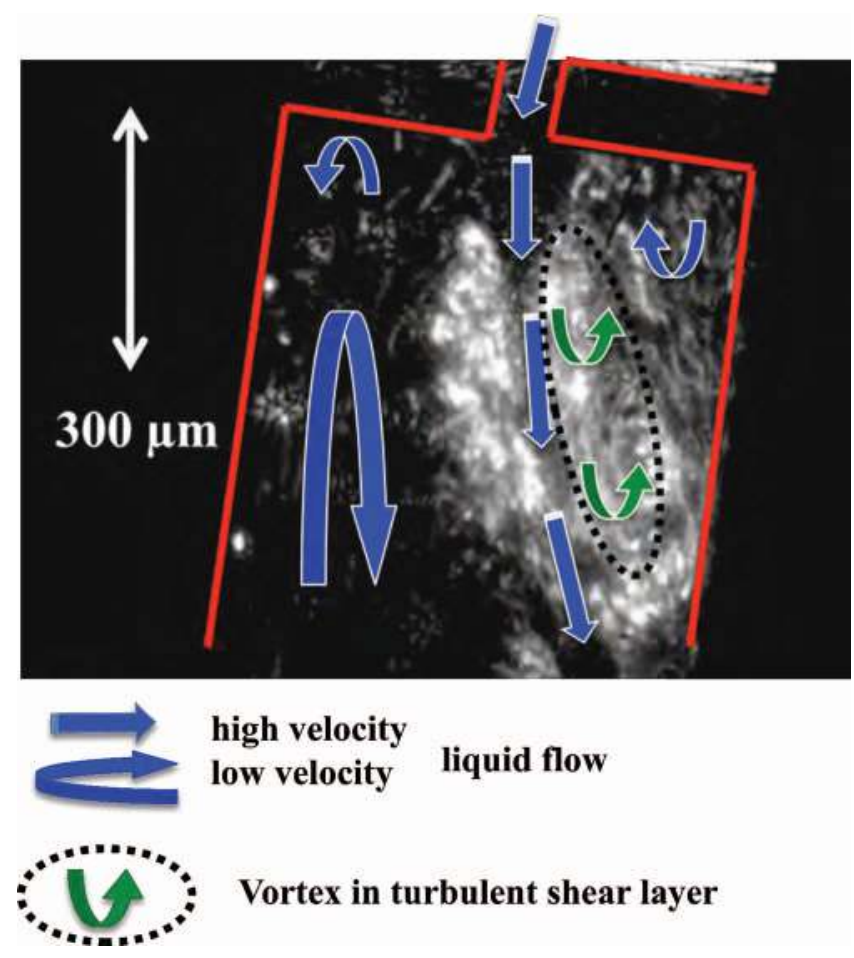

FIG. 11. Illustration of a cavitating flow through a microdiaphragm (enhanced online) [URL:
[ http://dx.doi.org/10.1063/1.3699067.1].

experiments, working with output pressures below $10^{5} \mathrm{~Pa}$ had enhanced the onset of cavitation. The authors concluded to the existence of steady twin vapor cavities merging at the exit of the orifice. Our captures go further into that analysis. The videos reported above correspond to hydrodynamic conditions that are similar to those in Ref. 2. They demonstrate the existence of a continuous circulation of fluid in the cavities delimited by the liquid jet and the lateral walls of the channel. The onset of cavitation takes place at the border between the merging liquid jet and the recirculating areas. The video enhanced online from Fig. 11 and the snapshots presented in Fig. 10 confirm these conclusions. A preferential low pressure area sucks the liquid flow and the resulting increase of the shear rate locks the impacting jet, until another fluctuation should trap it on the opposite wall.

\section{Microventuris}

Laminar separation occurs in the diffuser of the microventuri before the onset of cavitation ${ }^{4}$ that is depicted in Fig. 12, where the channel at time $t$ has been fed with a green fluorescent solution. Then, we have injected DI water. A while later $\left(t+t^{\prime}\right)$, just a residual green area remains in the diffuser, in a liquid cavity where the onset of cavitation is expected to arise. The photographs shown in Fig. 12 agree with the velocity map in Fig. 6(b).

A series of snapshots, recorded at $\mathrm{P}_{\text {out }}=\mathrm{P}_{\text {atm }}$ with an exposure time of $9 \mathrm{~ns}$ on a hybrid siliconpyrex microventuri, is presented in Fig. 13. The height of the Venturi is $\mathrm{H}=110 \mu \mathrm{m}$. The width of the throat is $\mathrm{w}_{\mathrm{o}}=45 \mu \mathrm{m}$. The angle aperture is $\alpha=3.5^{\circ}$, the total length of the diffuser is $5 \mathrm{~mm}$ so that the width at the exit of the diffuser is $\mathrm{w}_{\mathrm{L}}=654 \mu \mathrm{m}$. For this device, the desinence of cavitation occurs when the flow rate $\mathrm{Q}$ falls below $110 \mu \mathrm{l} / \mathrm{s}(\sigma>0.37){ }^{4}$ The values of $\operatorname{Re}_{\mathrm{v}}$ (Reynolds number in the throat), $\sigma$, and $\triangle \mathrm{P}=\mathrm{P}_{\text {in }}-\mathrm{P}_{\text {out }}$ are indicated on each picture. These pictures have been captured by decreasing the pressure drop, from a strong cavitating regime $(\sigma=0.08)$ to a lower cavitating regime $(\sigma=0.30)$.

Figure 13(a) demonstrates that a vapor cavity is attached to one side of the diffuser. Vapor clouds are shedded, convected downstream by the liquid towards higher pressure area where they collapse. 

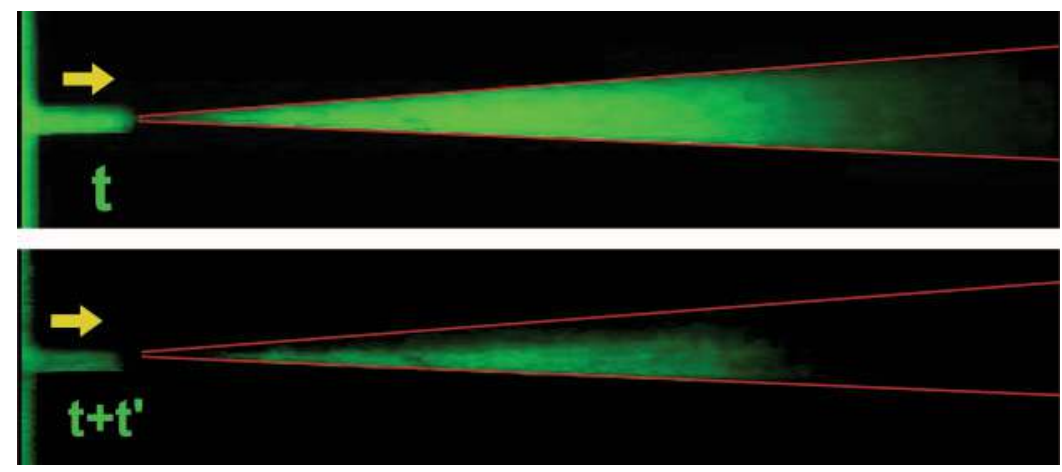

FIG. 12. Illustration of the laminar separation of a liquid flow downstream the throat of a microventuri. The lightest area (green) is a fluorescent solution.

The break-off mechanism and the impingement of the vapour cavity is observed in Figs. 13(b) and 13(c). These top views show a thin and elongated cavity being broken-off by a re-entrant liquid jet that is confirmed in Figs. 13(d) and 13(e) where $\sigma=0.30$. Figure 13(e) has been recorded just after the break-off of the cavity.

The unsteady behaviour of a sheet cavity under stationary conditions has been widely studied, because of the unfavourable consequences that the periodic collapse of shedded vapor clouds may have. ${ }^{9}{ }^{10}$ One must consider system and intrinsic instabilities, respectively. System instabilities refer to interactions between the cavity and the rest of the system. As an example, let us consider a gaseous cavity attached to the throat of a venturi; when the pressure decreases, the cavity volume increases and the incoming flow rate decreases. Such a variation of the flow rate goes together with an increase of the pressure since Bernoulli law. Then, the increasing pressure will reduce the volume cavity, so that the flow rate will increase again, and periodic variations take place. So, a self-oscillation of the cavity volume is reached, with an eigen frequency that depends on the characteristics of the hydraulic system.

Intrinsic instabilities refer to the cavity itself. The formation of re-entrant jet and the regular break-off of vapor clouds illustrate such an instability. During the growth of an attached cavity, a re-entrant liquid jet travels upstream along the wall, towards the leading edge of the cavity. The impingement of the jet on the cavity interface will cause the break-off and the convection of vapor clouds streamwise. Then, a new cavity starts to grow and the repetition of the mechanism gives way to a periodic shedding and collapsing of the clouds. The periodic shedding has been extensively studied on cavitating external flows across hydrofoils, ${ }^{10}$ and to a lesser extent on internal flows through nozzles or venturis. ${ }^{11}$

The shedding frequency $f$ can be characterized by the Strouhal number

$$
\mathrm{St}=\mathrm{fL}_{\mathrm{cav}} / \mathrm{u}_{\mathrm{o}}
$$

where $\mathrm{L}_{\text {cav }}$ is the maximum length of the cavity and $\mathrm{u}_{\mathrm{o}}$ is the velocity of the liquid upstream the cavity. Some authors ${ }^{10}$ assume that the velocity of the re-entrant jet is similar to $\mathrm{u}_{\mathrm{o}}$. In that case, $\mathrm{St}$ compares the time required by the re-entrant jet to pinch the cavity leading edge to the period of oscillation. As the re-entrant jet is caused by a pressure gradient that occurs once the cavity has began to grow, $\mathrm{St}<1$. Experiments performed up to now at macroscopic scale have been corroborated by numerical results, and Strouhal numbers ranging from 0.2 to 0.4 have been published. ${ }^{10}$ That constant order of magnitude confirm that re-entrant jet is an intrinsic instability.

The snapshots presented in Fig. 13 are consistent with a re-entrant liquid jet instability as the cause of cloud cavitation. High-speed camera observations were then necessary, in order to get an estimation of the periodic shedding and of the corresponding Strouhal number. For these observations, we have followed the procedure depicted in Fig. 8(b). The device under test was a pyrex-silicon-pyrex fully transparent venturi channel, whose sizes were $\mathrm{H}=145 \mu \mathrm{m}, \mathrm{w}_{\mathrm{o}}=28 \mu \mathrm{m}$, and $\mathrm{w}_{\mathrm{L}}=640 \mu \mathrm{m}$. 


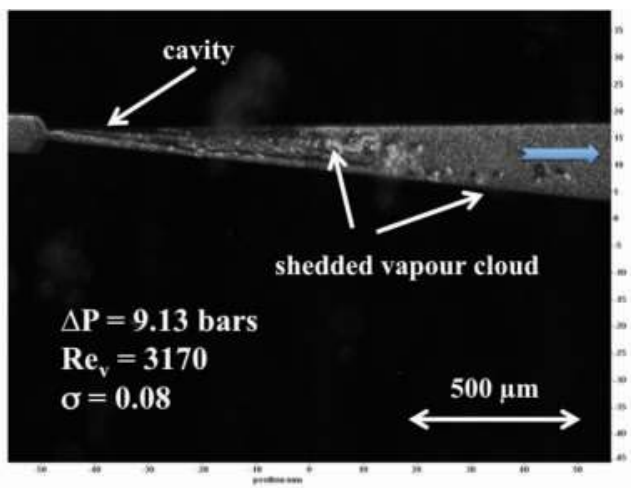

(a)

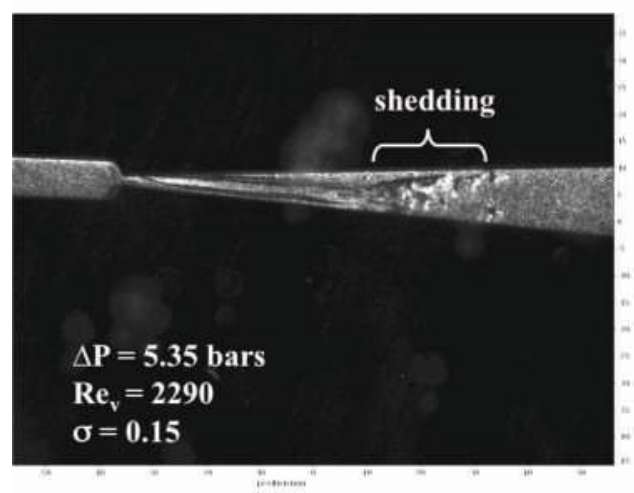

(c)

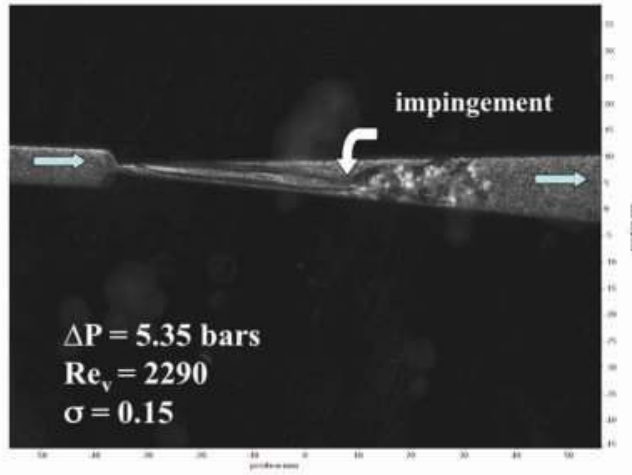

(b)

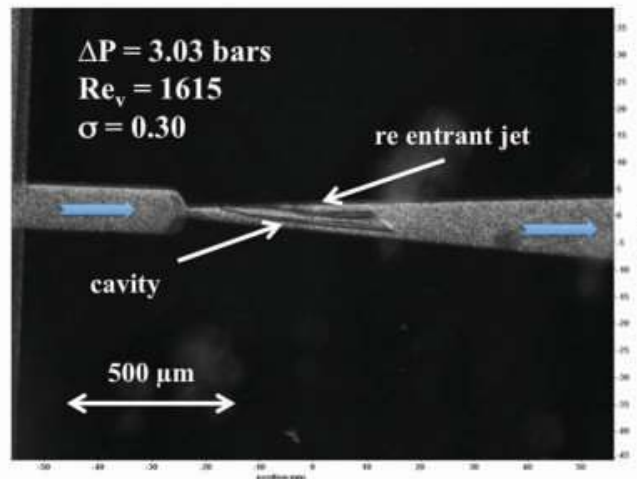

(d)

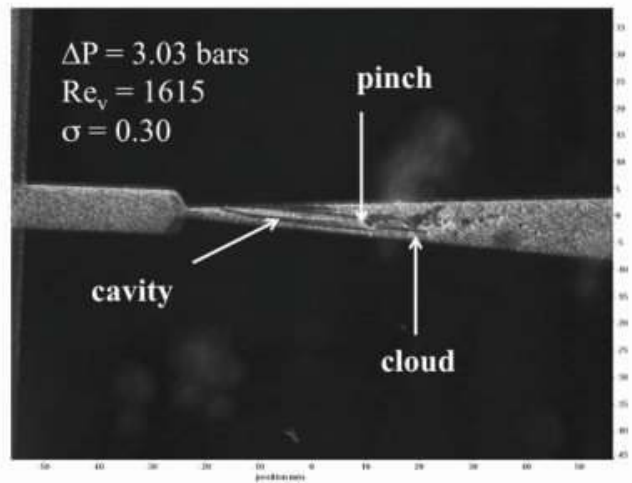

(e)

FIG. 13. Snapshots of cavitating two-phase flow downstream of a microventuri. The width of the throat is $\mathrm{w}_{0}=45 \mu \mathrm{m}$, the angle aperture is $\mathrm{a}=3.5^{\circ}$. The height of the device is $\mathrm{H}=110 \mu \mathrm{m}$.

The analysis of the data frame by frame gives an estimation of the frequency of the pulsation of the cavity volume oscillations. The shedding frequency was estimated from the variation of brightness recorded by the Phantom camera, because the amount of light transmitted to the camera is related to the amount of bubbles. An estimation of Strouhal numbers is then attainable. $\mathrm{St}_{\mathrm{cav}}$ is relative to the volume cavity oscillations. $\mathrm{St}_{\text {bub }}$ is relative to the shedding of bubbles from the cavity. 
TABLE I. Hydrodynamic parameters of a cavitating flow in a microventuri.

\begin{tabular}{lcccccc}
\hline \hline $\mathrm{P}_{\text {in }}(\mathrm{bars})$ & $\mathrm{P}_{\text {out }}($ bars $)$ & $\mathrm{Q}(\mu \mathrm{l} / \mathrm{s})$ & $\mathrm{Re}_{\mathrm{v}}$ & $\mathrm{St}_{\text {cav }}$ & $\mathrm{St}_{\text {bub }}$ & $\sigma$ \\
\hline 3.30 & 1.04 & 108 & 1248 & 0.04 & 0.003 & 0.29 \\
3.27 & 0.81 & 109 & 1259 & 0.05 & 0.002 & 0.22 \\
3.55 & 1.04 & 110 & 1271 & 0.04 & 0.002 & 0.28 \\
4.32 & 1.04 & 124 & 1432 & 0.04 & 0.003 & 0.22 \\
4.69 & 1.04 & 131 & 1513 & 0.04 & 0.04 & 0.20 \\
5.40 & 1.04 & 141 & 1629 & 0.03 & 0.03 & 0.17 \\
\hline \hline
\end{tabular}

We have considered that $\mathrm{L}_{\mathrm{cav}}=500 \mu \mathrm{m}$ is the average length of the cavity and $\mathrm{u}_{\mathrm{o}}$ is the liquid velocity in the throat. The results of experimental observations are reported in Table I.

The results obtained with $\sigma=0.17$ are presented in Fig. 14. A corresponding online movie, recorded with a rate of $28 \times 10^{3} \mathrm{fps}$ during $25 \mathrm{~ms}$ and with an exposure time of $9.82 \mu \mathrm{s}$, may be downloaded from Ref. 8. Since the sampling frequency was $28 \mathrm{kHz}$, a fast Fourier transform (FFT) could be applied to the data up to $\approx 10 \mathrm{kHz}$. The analysis frame by frame of the boundary of the gas pocket and the analysis of the brightness of the pictures gave two spectra which are intimately correlated, both exhibiting a fundamental frequency around $2100 \mathrm{~Hz}$. A high-frequency shedding is in phase with the cavity volume oscillations. So, we get similar Strouhal numbers $\mathrm{St}=0.03$ for both phenomena that are the pulsation of the sheet pocket and the shedding of the vapour clouds.

A sharp transition occurs when $\sigma>0.20$ and $\operatorname{Re}_{\mathrm{v}}<1500$. The frequency of the cavitating length is almost unaffected. However, the frequency of the shedding is dramatically reduced down to $\approx 120 \mathrm{~Hz}$. Two pictures are presented in Fig. 15. The dashed circle is a guideline to identify the location of the attached cavity (Fig. 15(a)). The bright area (Fig. 15(b)) is vapour clouds shedded at an eigen frequency of $120 \mathrm{~Hz}$. In these experimental conditions, we have $\sigma=0.22$ and $\operatorname{Re}_{\mathrm{v}}=1259$. A corresponding movie is enhanced online from Fig. 15. The time evolution of the length of the cavity and of the brightness of this movie is reported in Fig. 16. Figure 17 displays the corresponding spectra. The cavity volume oscillation is almost unaffected, but the peak around $2100 \mathrm{~Hz}$ is broadened. The period of the shedding has been considerably increased. The cloud shedding displays low frequency values with multi components that are no more negligible. Moreover,

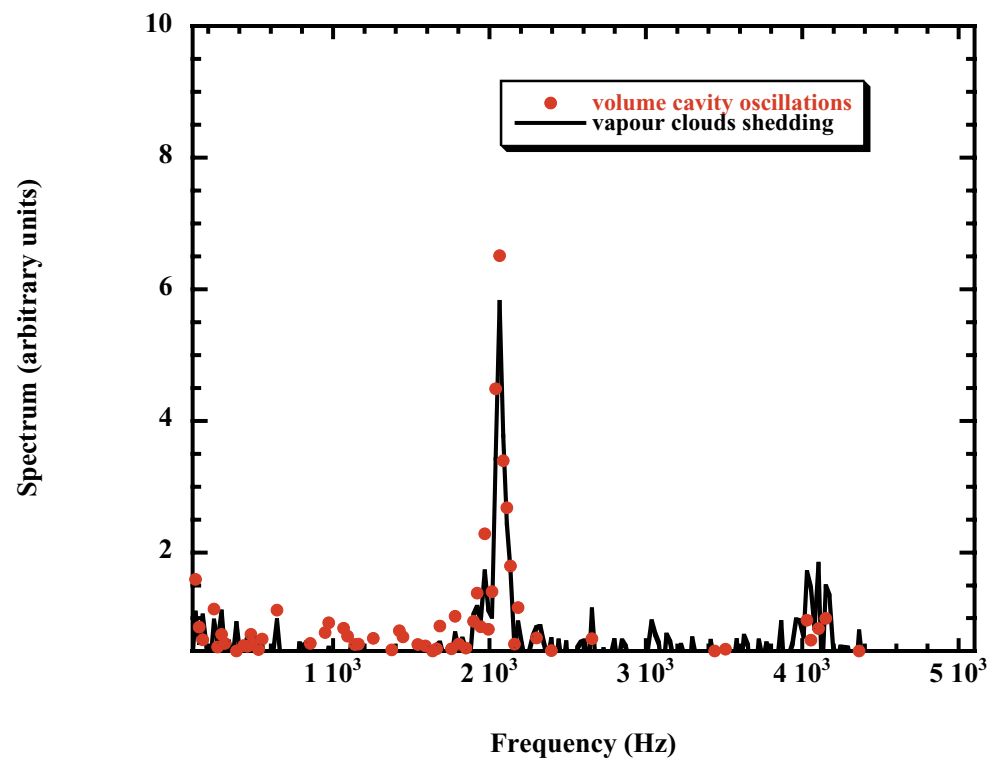

FIG. 14. Frequency spectrum for the cavitation length fluctuation (scattered points) and the vapour clouds shedding (solid line) at $\sigma=0.17$ for a microventuri. 


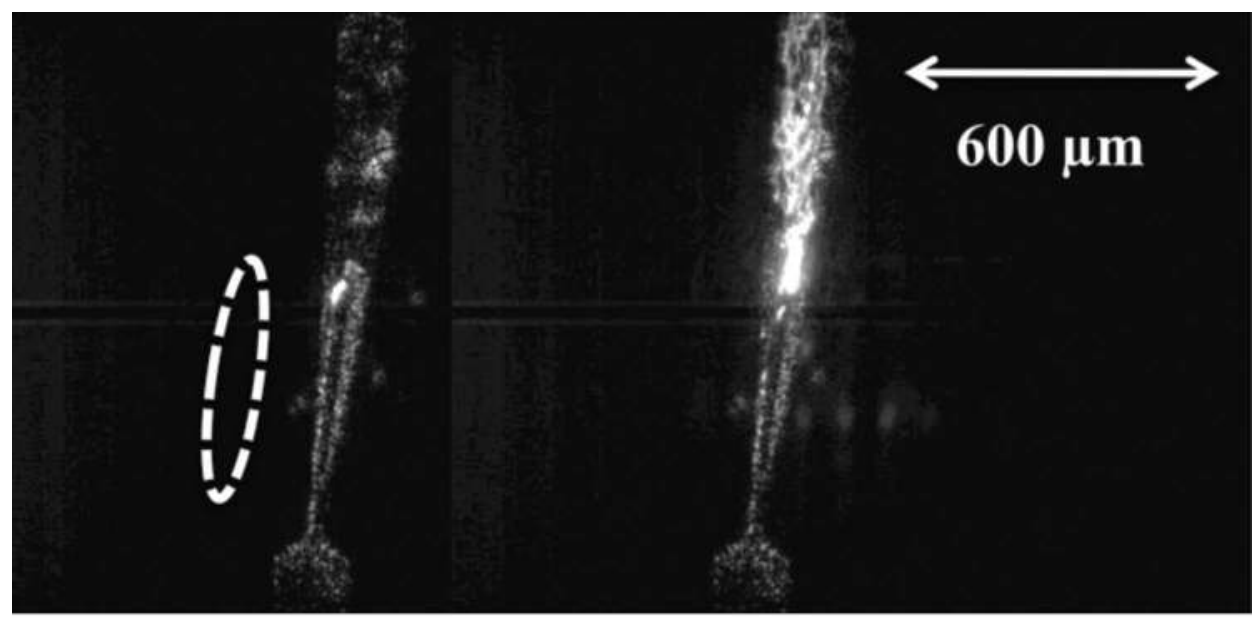

(a)

(b)

FIG. 15. Attached cavity (a) and vapour shedding (b) in a microventuri (Ref. 8 , movie recorded at a rate of $28 \times 10^{3} \mathrm{fps}$ during $25 \mathrm{~ms}$ and with an exposure time of $34.71 \mu \mathrm{s}$ ) (enhanced online) [URL: http://dx.doi.org/10.1063/1.3699067.2].

the duration of the shedding is now relatively long, as if accumulated gas had to be expelled from the venturi.

In a well-established cavitating flow regime, the Strouhal numbers related to the microventuri are one order of magnitude below the classical values published up to now. ${ }^{9-11}$

Sayyaadi ${ }^{11}$ has investigated the fluctuations of cavitating flows in a macroscopic venturi, by considering the fundamental as well as the multifrequency components of FFT spectra; at lower cavitation numbers, periodic shedding and collapsing of the vapor clouds was observed together with a re-entrant jet. The author concluded that $\mathrm{St}$ increases when $\sigma$ decreases. Our values of $\mathrm{St}_{\text {cav }}$ are constant, however, the range of $\mathrm{Re}_{\mathrm{v}}$ and $\sigma$ values considered here was too limited. So, we cannot confirm nor infirm the conclusions above. ${ }^{11}$

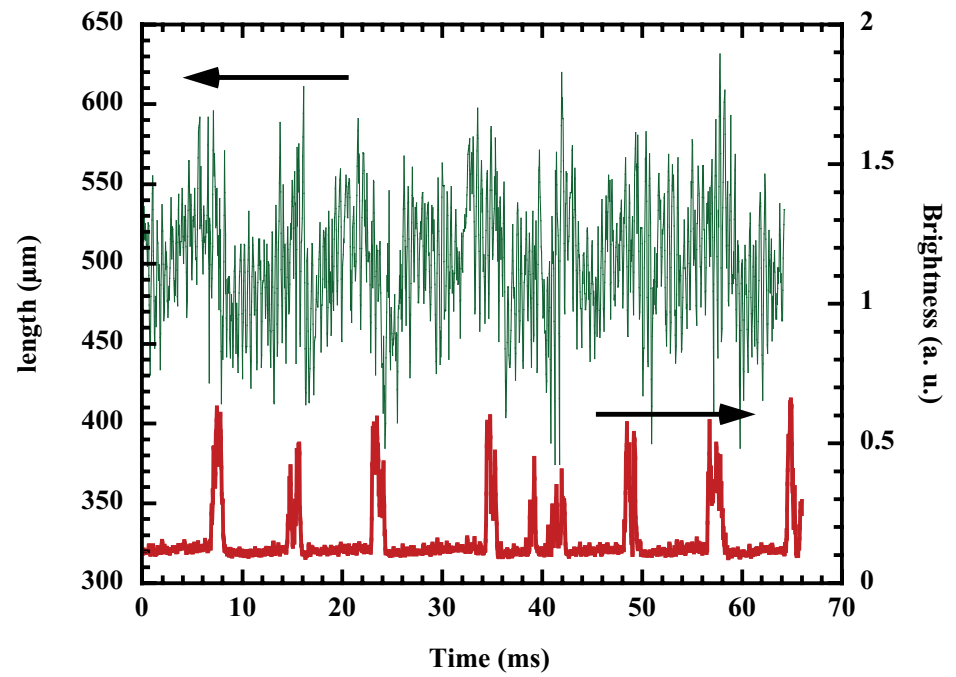

FIG. 16. Time evolution of the length of the cavity (upper graph) and of the brightness of the light scattered by a bubbly cavitating flow (lower graph) through a microventuri, at $\sigma=0.22$. The slope of the upper graph demonstrates that the cavity is growing, before shedding occurs at a fundamental frequency of $\approx 120 \mathrm{~Hz}$. 


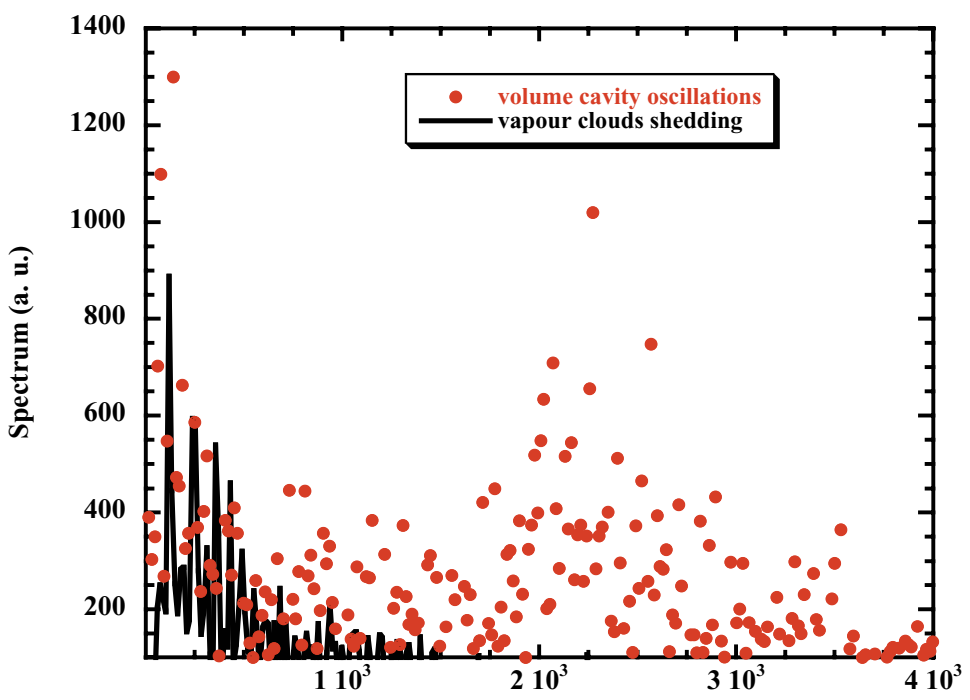

Frequency $(\mathrm{Hz})$

FIG. 17. Frequency spectrum of the volume cavity oscillations (scattered points, red) and of the vapour clouds shedding (solid line) at $\sigma=0.22$ for a microventuri. Compared to the data in Fig. 14, the frequencies of the shedding are now notably reduced.

Our results are consistent with the role of a re-entrant liquid jet, but give way to small Strouhal numbers and to an anomalous transition in the shedding mechanism. We believe that the mechanism observed here is the sum of system and intrinsic instabilities. A detailed calculation of the natural frequency of the hydraulic microsystem is out of the scope of this paper. However, the sub-millimeter sizes of the venturi and of the attached cavity are consistent with a natural frequency of $2 \mathrm{kHz}$, whereas macroscopic counterparts exhibit frequencies of only several Hz. So, we believe that the high frequency variations of the volume of the cavity are the cause of the periodic re-entrant jet. When the re-entrant jet has a momentum sufficient to pinch the rear part of the cavitation sheet and to break it off, a regular shedding occurs. At lower Reynolds numbers, the re-entrant jet is submitted to the effect of viscosity; then the shedding frequency is less regular. In that case, during a few periods, the quantity of vapour in the cavity increases and so does the volume of the cavity; above a critical length of the cavity, the re-entrant jet get sufficient momentum again, since the adverse pressure gradient is increased. A burst of vapour is then shedded. At last, below a threshold flow rate, the desinence of cavitation occurs.

There are some similarities with a phenomena featured as cavitation resonance, ${ }^{12}$ that is, an instability displaying a strong amplitude of pressure fluctuations at a natural frequency. That socalled resonance occurs over a limited range of cavitation numbers, just around the inception of cavitation. The authors claimed that the cavity cloud behaves as an exciter with a broad range of frequencies, in which one matches the eigen frequency of the hydraulic system. Our observations in Fig. 17 have demonstrated the existence of a periodic enhanced fluctuation at a natural frequency of the system, but without any cloud shedding. The physical mechanism of that so-called resonance in venturi devices may reside in an unsufficient re-entrant jet momentum.

\section{CONCLUSION}

Two-phase flow cavitating patterns have been clearly identified in microdiaphragms and microventuris fed with DI water. Numerical calculations have highligthened the fact that rounded corners at the edge of a microdiaphragm have a strong influence on the contraction coefficient of the liquid jet. As a consequence, the vortex region located just after the forward facing step is reduced. So, cavitation develops downstream in a very high shear rate recirculating area created by a 
deviation of the jet which is randomly sticked to one side of the channel. High-speed camera movies highlighten the low pressure vortices activity in the high shear layer. That activity is consistent with the continuance of cavitation, even if the pressure in the diaphragm has raised above $\mathrm{P}_{\text {vap }}$. The strong vortex activity is also consistent with the assumption that eddies can trap nanoparticles and form aggregates of sufficient size to release transition to cavitation, when using nanofluids. Concerning microventuris, the single liquid flow obeys a classical hydrodynamic behaviour depicted as well by numerical calculations as by experiments. Size effects have been observed in the two-phase cavitating flow. Very small Strouhal numbers are due to the union of microsystem and intrinsic unstabilities. The shedding process is due to a re-entrant jet whose momentum is monitored by the size of the microsystem and by the Reynolds number in the throat. Below a critical Reynolds number, viscous effects become predominant, and the break-off of the vapour cavity becomes less regular.

\section{ACKNOWLEDGMENTS}

This work was supported by the National Research Agency (Contract Lunaprobe No. ANR 09NANO-P057-36), the French National Center for Scientific Research (CNRS) (grant Illumination and Lunaparc), and the Rhône-Alpes Land. One of us (M.M.) acknowledges the financial support of the Joseph Fourier University of Grenoble. The authors acknowledge helpful assistance of Dr. L Vignal (instrumentation pool, LEGI) for the optical setup, and the technical support of the staff of the Nanofab facilities (Neel Institute). The authors acknowledge Dr. M. Bourgoin for having provided the Phantom camera and Dr. J.-P. Franc for useful discussions.

${ }^{1}$ C. Mishra and Y. Peles, “Cavitation in flow through a micro-orifice inside a silicon microchannel,” Phys. Fluids 17, 013601 (2005).

${ }^{2}$ C. Mishra and Y. Peles, "Flow visualization of cavitating flows through a rectangular slot micro-orifice ingrained in a microchannel," Phys. Fluids 17, 113602 (2005).

${ }^{3}$ C. Mishra and Y. Peles, "An experimental investigation of hydrodynamic cavitation in micro-Venturis," Phys. Fluids 18, 103603 (2006)

${ }^{4}$ M. Medrano, P. J. Zermatten, C. Pellone, J. P. Franc, and F. Ayela, "Hydrodynamic cavitation in microsystems. I. Experiments with DI water and nanofluids," Phys. Fluids. 23, 127103 (2011).

${ }^{5}$ L. C. Ganippa, G. Bark, S. Andersson, and J. Chomiak, "Cavitation: A contributory factor in the transition from symmetric to asymmetric jets in cross-flow nozzles," Exp. Fluids 36, 627-634 (2004).

${ }^{6}$ A. Sou, S. Hosokawa, and A. Tomiyama, "Effects of cavitation in a nozzle on liquid jet atomization," Int. J. Heat Mass Transfer 50(17-18), 3575-3582 (2007).

${ }^{7}$ U. Iben, A. Morozov, E. Winklhofer, and F. Wolf, "Laser-pulse interferometry applied to high-pressure fluid flow in micro channels," Exp. Fluids 50(3), 597-611 (2011).

${ }^{8}$ See supplementary material at http://dx.doi.org/10.1063/1.3699067 for videos.

${ }^{9}$ H. An and M. W. Plesniak, "Cavitation structures in a venturi flow with various backward facing steps," J. Fluids Eng. 130, 071304 (2008).

${ }^{10}$ D. F. de Lange and G. J. de Bruin, "Sheet cavitation and cloud cavitation, re-entrant jet and three dimensionality," Appl. Sci. Res. 58, 91-114 (1998).

${ }^{11}$ H. Sayyaadi, "Instability of the cavitating flow in a venturi reactor," Fluid Dyn. Res. 42, 055503 (2010).

${ }^{12}$ S. C. Li, Z. G. Zuo, S. H. Liu, Y. L. Wu, and S. Li, “Cavitation resonance,” J. Fluids Eng. 130, 031302 (2008). 